\title{
Research on the Construction of China Capital College Sports Network Information Platform
}

\author{
Yuan Zhang \\ China University of Geosciences (Beijing) \\ Sports Department \\ Beijing, China \\ e-mail: zhangyiyuan1118@163.com
}

\author{
Wenge Yang \\ China University of Geosciences (Beijing) \\ Sports Department \\ Beijing, China \\ e-mail: ywg2118@sohu.com
}

\begin{abstract}
This paper adopts expert interview and computer networking login statistical investigation method. Depended on the analysis of the status of network information of capital college, this paper discusses construction of the capital university sports network the information, and puts forward the strategy of sustainable development. Through to sports department information web site investigation of 46 colleges in Beijing , this paper puts forward "serve students", "service to the society" as the starting point and "make people the center", "the health first" as the guiding ideology in the construction of the department in the future of sports information website. College sports information website should include seven aspects of the best function modules: sports information management system, multimedia teaching system, teaching database management system, teaching management system, students' evaluation management system, mass sports management system, sports information feedback system.
\end{abstract}

Keywords-sports construction; network construction; high-level education; school sports

\section{INTRODUCTION}

"Sports information" is the application of characters, data or signal etc form to show all kinds of interconnected sports phenomenon and law of the general characteristic content through some transmission and processing. The basic contents of sports information including macro decision management information, mass sports information, sports education information, competition sports information, sports industry information and the sports science and technology information and so on various information content. Characteristics of sports information is valuable and delivery. It attaches to all forms of carrier and have plasticity, multiple efficiency . It also exists devaluation and pollution phenomenon ${ }^{[1]}$. Along with the rapid development and breakthrough of computer, network communication, remote sensing technology, digital media and a series of technology, especially for the great success of Internet, the strong power of information in all fields is obvious. Sports information also presents the networking tendency. The extensive use of information network could accelerate sports information resources development and utilization. It also realizes the height of the sports information resources sharing and further optimization of sports resources allocation. It finally increases the whole society to sports resources efficiency ${ }^{[2]}$. College sports is no exception as the one of the beneficiaries. Information technology in college sports, whether in the change of the traditional teaching mode and teaching efficiency, or update management ideas and raise the level of management, are vital role. The level of college sports network informationization represent the degree of the college physical education, sports decision management information and sports teaching environment information. It also reflect the ability of the various comprehensive evaluation awareness of the school staff and students. Information level is the concept of quality. The network information is multiple perspectives, all-round system. It included in all aspects of network activity content and process. $^{[3]}$

The success of the Olympic Games held in 2008 and the national sports career development "1025" planning (article sixty-one) proposed: "advance sports information construction". These brought opportunity for development of the capital university sports information network. We think that the capital of college sports education scientific research, teaching reform, teaching management, and sports training, sports competitions depend on sports information resources. Especially with the rapid development of information technology and modern science, network has become necessary information tools in life. The utilization of the sports information resources for physical education teachers has increased year by year. But, compared with the overall national level, the capital college sports information development is far behind. The specific performances include: sports information theory research and utilization value is not high, The sports information of hardware and software development is relatively backward; Information quantity and quality is not high, high quality of the physical website construction is not enough and has not yet realize college sports information; The database construction cannot have full service ability. Therefore, how to scientifically develop and use capital university sports information resources and serve the capital university better, will be the priority in front of the capital physical educational teaching management departments and sports education workers.

Implying modern information network technique to build the capital university sports network information 
platform has far-reaching significance. At the beginning, it provide high quality service platform for the capital university talent of education high quality. And it can play a positive role to improve the quality of college educational sports. It can combine school sports education. family education and social education sports, especially public sports media recessive education. It also realize sports education of human, material resources multiple level development and rational configuration. What's more, It adds innovation superiority for modern sports education. Finally, it provides the reference for the national university sports network information platform construction.

\section{RESEARCH OBJECTS AND METHODS}

\section{A. Research objects}

The research objects are 46 colleges extracted from a list of 89 ordinary colleges which have the entrance qualifications of higher educational background published by ministry of education in 2011.It accounted for $47.2 \%$ of the total. Of which are 33 ordinary colleges and universities (58 total), accounting for $56.9 \%$ of ordinary colleges and universities; the number of Ordinary vocational colleges is 12 (of 25), accounting for $48 \%$ of ordinary vocational colleges; Independent Institute 1 (of 5), accounting for $20 \%$ of Independent Colleges.

\section{B. Methods}

- Literature and data. Through access to the Internet and plenty of related literature about Information classes and sports information class on the core journals

- Survey and interview. Collected a total of 21 experts in various institutions at all levels who were interviewed, including two well-known professor, five professors, 11 associate professor, 2 lecturers, 1 assistant; These experts are all front-line teachers. Summarize the results of interviews and finishing.

- Using the computer technology and network communication technology, the capital university sports department website were investigated online.

- Structured design methods.Structured system analysis and design method is classical method of software engineering field. Structured analysis and design method is based on photo-based DFD. The system is divided layer by layer into more appropriate size, function specific, and easy to achieve a certain independence of modules [4].

- Mathematical statistics.In the process of developing information systems, the common statistical methods have be used, such as average, sum, etc..

\section{THE RESULTS AND ANALYSIS}

\section{A. The results}

At first, the homepage of sports information network of the 46 colleges and universities in the capital treats into four categories: Category 1, sports information network which is the second level website in school's website; Category 2, no homepage of sports information network but some introduction in the school's website; Category 3, the sports department which is shown in the homepage of school's website without related presentations; Category 4, no sports department information in school's website(TABLE I ).

TABLE I. HOME PAGE OPEN LIST SITUATION IN CAPITAL 46 UNIVERSITIES SPORTS DEPARTMENT INFORMATION NETWORK

\begin{tabular}{cllll}
\hline & $\mathbf{1}$ class & 2 class & 3 class & 4 class \\
\hline Colleges and Universities & 28 & 5 & & \\
Vocational Colleges & 5 & 5 & 2 & \\
Independent College & & & & 1 \\
\hline
\end{tabular}

Note: This table statistics deadline for August 25, 2011. 1 class :home page ; 2 class: There are introduced; 3 class: No home and introduction; 4 class: No sports department information

As can be seen from the above statistics, the first class has 33 colleges and universities, accounting for $71.74 \%$ of schools surveyed; Category 2 of 10 colleges and universities, accounting for $21.74 \%$ of schools surveyed; Category 3 has two universities, accounting for the survey $4.34 \%$ of schools; Category 4 has a university, accounting for $2.17 \%$ of schools surveyed. This ratio can be seen that the capital of college sports departments have information on the sports network awareness. For Category 1and Category 2, 43 colleges and universities have found the home page of the sports sector, the contents of the home page design is relatively simple, focusing on the transmission of basic information, such as profiles, teaching, community, training profile, content is not rich enough (TABLE II); information updates is not in time, $80 \%$ information content of 21 colleges and universities is a year ago, accounting for $48.8 \%$ of schools surveyed; 25 colleges and universities are still using static web pages, old technology, accounting $58.1 \%$ of the school survey; 30 colleges and universities lack the rough beauty of web design, impact on the user's use, accounting for $69.8 \%$ of schools surveyed. Sports network information services are not fully used.

TABLE II. BEIJING 43 UNIVERSITIES SPORTS DEPARTMENT HOMEPAGE CONTENT CLASSIFICATION.

\begin{tabular}{cll}
\hline Webpage content & $\begin{array}{c}\text { sports department } \\
\text { webpage }\end{array}$ & Percentage \\
\hline Profile & 40 & 93 \\
Sports news & 15 & 34 \\
Organization & 30 & 70 \\
Physical education & 26 & 60 \\
Mass sports & 21 & 48 \\
Sports training & 22 & 51 \\
Venues and facilities & 18 & 42 \\
Sports knowledge & 10 & 23 \\
Physical health & 7 & 16 \\
Miscellaneous & 10 & 23 \\
\hline
\end{tabular}

Results from the above statistics, what can be seen clearly is that the capital of college sports information resources is relatively weak, the system is not perfect, and management has been lagging behind, so they cannot form a complete system of sports information resources available to university students. This makes it impossible to meet the physical teachers to improve teaching quality, research capacity, level of training, race results, and 
students learning needs of sports knowledge, and the university's sports information update is slow. It will not be able to meet the student's fitness for the new method, the contents of fitness, fitness program, fitness theory, prevention and treatment of sports injuries, the referee rules appreciate the desire to learn the knowledge of the game, thus the impact is: (1) Part of the physical education teachers knowledge of the aging phenomenon is more prominent, which is constraining bottleneck in college sports reform;(2) The student's theoretical knowledge and lack of fitness and cannot be scientific, systematic and comprehensive physical exercise; (3) Expand the physical education teaching and learning the contradictions; (4) It Cannot meet the educational needs of college quality; (5) Low level of sports science, the results less.

\section{B. The campus sports information platform development research}

College sports network information platform construction includes three aspects: firstly, Internet, configuration scheme; secondly, needs analysis; thirdly, database development plan. fourthly, information system design and development.

- Internet configuration scheme

Using Internet communication standard of the college and sports information system established by high quality WWW information circulation pattern, can achieve quick and low cost effect. It avoid the repetitive construction of the hardware platform and communication network environment. It also can be built together by related departments and units. The school sports information content can be connected to the sports information platform or remote related units on the mirror site by direct hosting, web hosting and any ways. It can realize online resources sharing. Through the Microsoft ACCESS 2000 / SQL 2005 + ASP VBScript it can realize to update the sports information and the various functions. After the study analysis, services provided by campus sports information platform and the required supporting software and hardware showed in TABLE III.

TABLE III. SERVICES PROVIDED BY CAMPUS SPORTS INFORMATION PLATFORM AND THE REQUIRED SUPPORTING SOFTWARE AND HARDWARE

\begin{tabular}{|c|c|c|}
\hline $\begin{array}{c}\text { Provides } \\
\text { basic } \\
\text { services } \\
\end{array}$ & The service content & $\begin{array}{l}\text { Required software and } \\
\text { hardware }\end{array}$ \\
\hline DNS & Provide Internet analytical & $\begin{array}{c}\text { Main/Auxiliary DNS } \\
\text { server }\end{array}$ \\
\hline WWW & Campus network center WWW & WEB server \\
\hline $\begin{array}{l}\text { WWW } \\
\text { personal } \\
\text { space }\end{array}$ & Free personal & $\begin{array}{l}\text { WEB personal server } \\
\text { space }\end{array}$ \\
\hline FTP & File download & The FTP server \\
\hline $\begin{array}{l}\text { PROXY } \\
\text { server }\end{array}$ & $\begin{array}{l}\text { Accelerate INTERNET lines } \\
\text { visit,Improve direct visits of } \\
\text { INTERNET lines. }\end{array}$ & PROXY server \\
\hline BBS & Electronic bulletin board & BBS server \\
\hline FILE & FILE server & NOVELL/NT/LINUX \\
\hline
\end{tabular}

As shown in figure 1, college sports information platform is applied in the Internet environment and is typical of browser/server (B/S) model [5]. Server used Windows 2003 Server + IIS 6.0 building Intranet network, Microsoft ACCESS 2000 or Microsoft SQL Server 2005 as data storage, ASP VBScript as Server programming language, JavaScript as client script language, have advantages that the traditional network doesn't have. The first advantage is opening structure. Intranet based on TCP/IP protocol, can span different hardware and software platform. It can operate independently and can be in a firewall under the protection of the Internet connection.

The second advantage is the utilization of advanced browser/server mechanism. Intranet in the network applications, development client program is not required. Any network terminal just use the browser to undertake network application. It is simple and quick. Whether on the development or applications it will greatly reduces the difficulty. The third advantage is low cost. Intranet system is easy to form and manage and its cost is low. Microsoft's Intranet technical support widely and its has many development tools, Windows 2003 operating system itself is integrated Web server software IIS 6.0, and terminal of the browser IE is completely free.
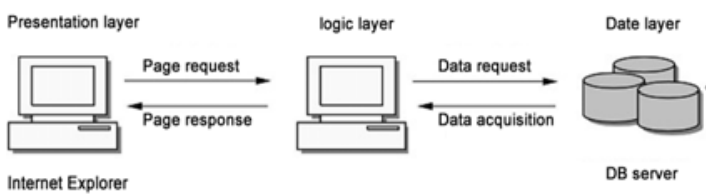

Figure 1. The B/S Model Schematic Diagram.

- Requirement analysis

Results of 21 expert's interview found that demand for sports information in colleges include 9 modules : Homepage, Sports news (inside and outside),Sports teaching materials, High level sports teams, Sports associations, Student information management, Instructional video, Online comment, Sports Forum, as shown in TABLE IV.

TABLE IV. 21 EXPERTS ON UNIVERSITY SPORTS INFORMATION NEEDS SURVEY

\begin{tabular}{|c|c|c|c|c|c|c|c|c|}
\hline & \multicolumn{2}{|c|}{$\begin{array}{c}\text { Very } \\
\text { needed }\end{array}$} & \multicolumn{2}{|c|}{ Needed } & \multicolumn{2}{|c|}{$\begin{array}{c}\text { Relatively } \\
\text { needed }\end{array}$} & \multicolumn{2}{|c|}{ Unneeded } \\
\hline & $\begin{array}{l}\text { The } \\
\text { num. }\end{array}$ & $\%$ & $\begin{array}{l}\text { The } \\
\text { num. }\end{array}$ & $\%$ & $\begin{array}{l}\text { The } \\
\text { num. }\end{array}$ & $\%$ & $\begin{array}{l}\text { The } \\
\text { num. }\end{array}$ & $\%$ \\
\hline Homepage & 21 & 100 & & & & & & \\
\hline News & 17 & 81 & 3 & 14 & 1 & 5 & & \\
\hline Teaching & 20 & 95 & 1 & 5 & & & & \\
\hline Teams & 17 & 81 & 1 & 5 & 3 & 14 & & \\
\hline Associations & 19 & 90 & 1 & 5 & 1 & 5 & & \\
\hline
\end{tabular}




\begin{tabular}{ccccccccc}
\hline Management & 16 & 76 & 2 & 9.5 & 2 & 9.5 & 1 & 5 \\
Video, & 19 & 90 & 1 & 5 & 1 & 5 & & \\
Online & 16 & 76 & 2 & 9.5 & 2 & 9.5 & 1 & 5 \\
Comment & & & & & & & & \\
Sports & 16 & 76 & 3 & 14 & 1 & 5 & 1 & 5 \\
$\begin{array}{c}\text { Forum } \\
\text { Campus } \\
\text { Sports }\end{array}$ & 10 & 48 & 3 & 14 & 4 & 19 & 4 & 19 \\
$\begin{array}{c}\text { Facilities } \\
\text { Campus } \\
\text { Sports }\end{array}$ & 7 & 33 & 6 & 29 & 5 & 24 & 3 & 14 \\
Culture & & & & & & & & \\
Others & 9 & 43 & & & & & & \\
\hline
\end{tabular}

- $\quad$ Build sports information platform database

Based on the campus sports information including contents, we established four database to make it more efficient to read, store and manage their content-Sport database, BBS database, Students' scores datbase, Games management database. The above four database fully meet the needs of campus sports information, and the database structures are shown in Figure 2-1.2.3.4. This database was produced by Microsoft ACCESS 2000. If the amount of data access over 2000 times/S, ACCESS would be not stable. We can upsize to Microsoft SQL 2005, so that data access is stable. But the SQL database is not free. It will increase development costs.

- The composition of the campus sports information platform system

According to the demand and the B/S network model, campus sports information platform is divided into three modules: Data interpretation module, Information management module, Page processing module. Information management module is to provide data manipulation service to the webpage administrator. Data interpretation module is to provide a description for the data users, shows that the data is what it is for information. Page processing modules is to provide users with elegant easy browsing display.

According to the model of sports information, can classify sports information into five categories: Text, Images, Videos, Files, Data. Each category on data processing, data interpretation, page processing has its own way.

This system have 9 parts: Information management system of physical education(IMSP), Multimedia Teaching System(MTS), Teaching Resources Management System(TRMS), Teaching Management System(TCMS), Extracurricular sports management system(ESMS), Sports team management system(STEMS), Physical fitness Evaluation management system(PEMS), Physical education feedback system(PEFS), Sports Forum. Show as in Figure 2.

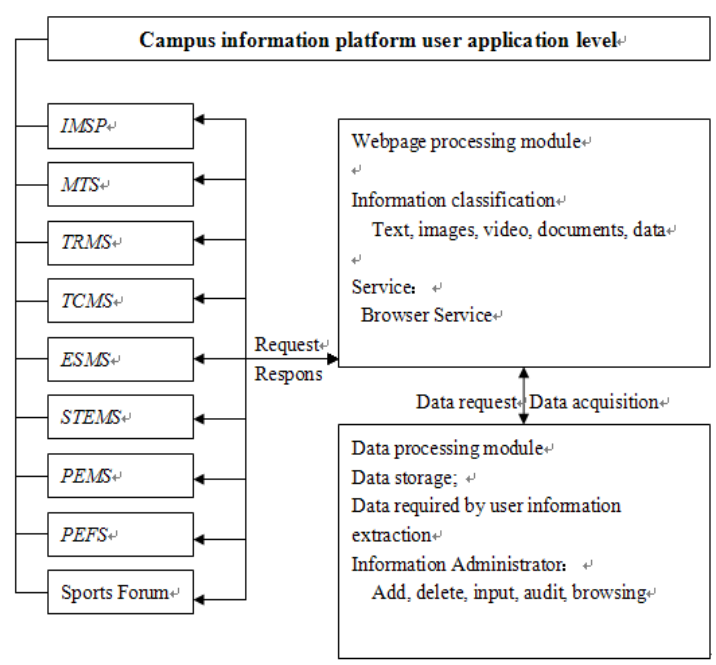

Figure 2. System Function Modules.

Sports Information Management System:

This subsystem is mainly to provide some basic information about the situation, which includes school sports department briefing; school teaching, group training, competition news, the implementation of education reform, information and peer learning. The subsystem can achieve the requirements of the sports information management features such as input, add, delete, edit, query, print and other functions.

Multimedia Teaching Subsystem:

Sports programs through the use of courseware, information resources, provides students with a broad space for learning, which includes sports knowledge, health knowledge, exercise of the methods, principles, technology and other aspects.

Teaching resources database management subsystem:

The main function of resource library system is to collect, management, retrieval and use a variety of teaching resources. The system includes the construction of teachers team, professors style, teaching facilities, network examination management and other aspects.

Physical education management subsystem:

The subsystem functions have: the detailed plan in one semester of physical education according to sport teaching program , management sports scores of students, sports scores for students input, edit, query, and performance reports printed out the end of the semester sports in each class.

Extra-curricular sports management subsystem:

The subsystem is to manage extra-curricular sports activities of students .Each school sports club is recorded details, including each club's instructor, the joining students and the plan of main activities. In addition, it also can statistics of the percentage of the students in each the clubs, the proportion of boys and girls .It can also Manage and record all of the students each semester events, for example, school sports, basketball, volleyball and the training school and other sports clubs. 
Sports team management system:

The subsystem is a high-level sports team management which includes the high school sports teams for more information with coaches, athletes, competition results, coaches develop training plans.

Sports information feedback subsystem:

The system solves the problems encountered by the students in physical activity and answers questions.

Physical evaluation of management subsystem:

The subsystem can record each student's physical health, including height, weight, lung capacity, chest and other health indicators, according to the state of the "National Student Physical Health Standards", and calculate the scores for each student each semester. Students can always check the physical health status, and out of exercise prescription, fitness later in the guidance.

Sports Forum subsystem:

This subsystem provides students and students, teachers and students, teachers and teacher information exchange platform. It would realize the purpose of communication at home. It provides questionnaire function for physical education teachers to promote physical education teacher research capabilities.

\section{Website development}

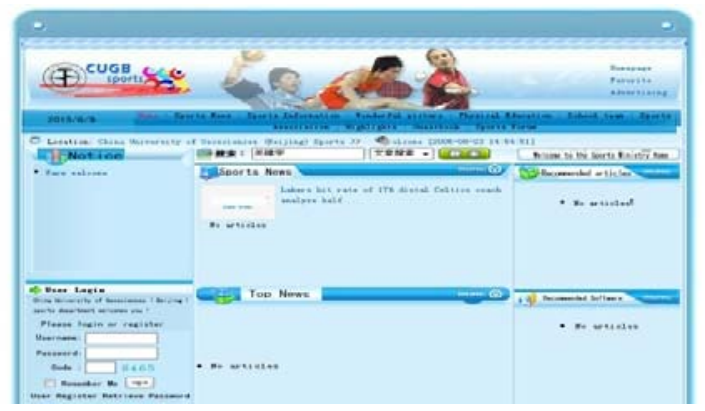

Figure 3. Home page.

\section{CONCLUSION}

\section{A. Survey results}

The findings from the current investigation, the network of the capital ocollege sports information lags far behind other professional development.

\section{B. The future focus on the development of sports information}

Sports department of the information network is basically stuck in the development of basic information. During the future development of the sports department in the information network, its purpose is to serve the students, to serve the community. So home web should include 9 areas: information management systems, multimedia teaching system, teaching resources database management systems, learning management system, management of physical evaluation system, extracurricular sports management system, high-level sports teams management system, sports and information feedback system, sports forum. Do good job regularly in needs relationship of sports information to change the content column and provide a better service.

\section{Increase investment}

The overall development trend of information technology in Capital College Sports Network is on the rise, but the speed is low. The construction, development, survival of capital college sports network information needs the decision-makers' decision-making and implementers support. It is necessary to use a long-term vision to consider the school and sports department development.

\section{REFERENCES}

[1] Zhang Li, etc. The Reflection on development of China's sports information service industry [J]. Sports science and technology: 1999.7, 19 (4) : 81.

[2] Zhou Lanjun, Zhang Tianjian. Present situation and countermeasures research on the development of domestic and international sports and information network [J]. Journal of Guangzhou sports institute. 2003, (6) : 5-7.

[3] Thomas B. Tomorrow's faces--information level open the key of post-modern information age [M]. Beijing: Peking University press, 2000. On page 8 .

[4] Dong Lungong. Sports information management theory and research on the application of systems development [D]. Beijing sport university 2002.

[5] Wu ping, Le Jiajin. Design and implementation of the three layer sports information processing system based on B/S structure [J]. Journal of Donghua university (natural science edition). 2006 year 04 period 